\title{
4
}

\section{Partnerships between Government and the Third Sector at a Subnational Level: The experience of an Australian subnational government}

\section{David J. Gilchrist}

\section{Introduction}

Since World War II and the establishment of the Welfare State in countries influenced by the United Kingdom, including Australia, government has used not-for-profits (NFPs) or the NFP sector to deliver services associated with much of its social policy. While the extent of this phenomenon has waxed and waned in accordance with the political philosophy of each successive party in government, the delivery of services via this sector has been increasing, particularly since the 1980s, and is a source of considerable political angst (Mendes 2008; Productivity Commission 2010).

Primarily, this angst arises because governments wish to continue to provide services via the NFP sector but also reduce expenditure, control service delivery and retain the political capital derived from such activities. On the other hand, NFPs struggle constantly with poor resourcing, increasing pressure from governments to perform 
more with less, the provision of services in accordance with their mission, mission creep caused by funder priorities and, sometimes, religious and other drivers (Salamon 1995; Frumkin 2002; Barraket 2008). Overall, Young (2006), in discussing the US experience, identifies that NFPs can have several relationships with government at once, neatly identifying them as adversarial, complementary or supplementary. This complexity ensures there is constant tension between governments and NFPs.

The Australian experience is somewhat similar and there has been a constant drive to find an arrangement for improving the governmentNFP relationship in the interests of achieving better outcomes for communities. Reverting to received wisdoms as they might be from time to time, at the highest level, concepts such as government-NFP partnerships, market-based economic solutions and private sector financing options have all been considered (Garton 2009; McGregorLowndes 2008; Roth 2011; Center for Law and Social Policy 2014). Emphasising the importance of the NFP-government relationship, these ideas have been implemented and examined at the highest levels, including formal parliamentary examinations (see, for example, OAG WA 1998, 2000, 2003, 2012, 2013a, 2013b; PAC WA 2000; VAGO 2013).

This debate has most recently seen the manifestation of the Delivering Community Services in Partnership (DCSP) Policy in Western Australia, a small state by population if not by geographic size in the Australian federation. It is this policy, and the author's longitudinal evaluation of the outcomes achieved to date under the policy, that is the central focus of this chapter. Further, the research itself uniquely evaluates both the government side of the DCSP Policy and the NFP sector side so a more holistic view of the impact of the DCSP can be understood. While comments are made here relating to the government side, it is in fact the NFP side that is primarily evaluated in this chapter due to space constraints - the government side being evaluated in future outputs.

This chapter is divided into five sections. In section two, I review the DCSP Policy and identify its major elements. In section three, I provide an overview of the review methodology, and in section four, I discuss the findings. Section five consists of concluding remarks. 


\section{The DCSP Policy}

In Western Australia, in 2011, the state government issued the DCSP (WA Government 2011). This policy was arrived at after the incoming Barnett Government (elected in 2008) implemented an audit of all government activity and expenditure. The resulting audit report identified a number of recommendations pertaining to the NFP sector and its relationship with government (Economic Audit Committee 2009).

Of the Economic Audit Committee's major findings, those most important to the NFP sector included (paraphrased and condensed):

1. That the NFP sector is best placed to provide services to the community.

2. As such, government should pass more services over to the sector.

3. Such services should be purchased via the identification of a supplier-sustainable price.

4. Services should be funded by individually recognising resources allocated to recipients (individualised funding).

5. Recipients should have control over purchase decisions and the services they receive (person-centred care).

6. The administrative burden created by contracting processes should be minimised.

7. The evaluation of programs and funding should be undertaken via the examination of outcomes rather than outputs.

The DCSP Policy was developed such that it encapsulated the principles above. It was implemented after the establishment of the Partnership Forum comprising NFP representatives and senior public sector personnel. This forum continues to meet regularly and subgroups of its members have been created to review certain aspects of the implementation of the policy, including identification of outcomes.

The government instructed all of its agencies involved in the provision of funding to, or service procurement from, NFPs for service delivery to implement the requirements of the policy. It also established a unit within the Department of Finance with responsibility for oversight of the transition, to provide training and resources to both the public 
and the NFP sectors to support implementation, and to provide ad hoc advice. The Forum established a subgroup focused on the evaluation of the implementation of the DCSP Policy.

Commensurate with the audit committee's findings and the DCSP Policy's prescription of maintaining a supplier-sustainable price for service purchases, the WA Government provided top-up funding to meet systemic underfunding identified via the Partnership Forum. It made provision in the 2010-11 and 2011-12 state budgets for $\$ 600$ million in additional funding in two tranches, Component I and Component II (Gilchrist and Knight 2013b). Component I was paid during the 2011-12 and 2012-13 financial years. Component II was paid during the 2013-14 financial year.

Critically, the Parliament required the government to undertake an evaluation of the DCSP Policy annually for five years, and this chapter reports the first three years of evaluation findings - relative principally to the NFP side - of that evaluation carried out by the author.

\section{Review methodology and response rates}

As described above, the DCSP Policy is to be reviewed annually for five years beginning in 2012. To date, the author has completed three reviews, one each for 2012, 2013 and 2014 (Gilchrist 2013; Gilchrist and Knight 2013b; Knight and Gilchrist 2015). Each review is undertaken and a report created that is, initially, provided to the Partnership Forum and then published. Typically, these reports have been published quite late in the year of evaluation or early the next year. The results of the 2014 evaluation are the ones explored in this chapter as these encapsulate the 2012 and 2013 results, compare the three years and provide a longitudinal view.

The evaluation consisted of two main tasks. NFPs that had service agreements based on the new policy and which received Component I funding were surveyed. We also surveyed and interviewed state government agencies that administer contracts for community services provided by the NFP sector. In other words, the research focused on both the commissioners and the service providers in an attempt to 
assess the full implementation effects. All research activities were undertaken after meeting Curtin University's ethics policies and processes, and after achieving an ethics clearance.

Overall, the adoption of the DCSP Policy was intended to increase the sustainability of the NFP sector, reduce the administrative burden and build capacity for increased work to be transferred from the government sector to the NFP sector. As such, the evaluation process was aimed at assessing, on an annual basis, the extent to which the above had been achieved. Therefore, in undertaking the review of the DCSP Policy, focus was placed on outcomes achieved in relation to the following areas, which were also the central focus of the policy itself:

1. sustainability;

2. DCSP Policy implementation (principally in relation to the establishment of outcomes-based contracts and increased service delivery); and

3. the impact of the DCSP Policy on NFPs and government agencies.

\section{State government agency interviews and surveys}

A unique aspect of this research program was the fact that the examination considered both NFPs commissioned by government agencies and the commissioning agencies themselves. While it is reiterated that this chapter focuses on the NFP side of the research program, this section very briefly describes the research methodology employed in examining the commissioning government agencies applying the DCSP Policy, to place the results of the research pertaining to the NFP sector in context, and to better explain and demonstrate the findings associated with the NFP sector.

The methodology employed in 2012 in evaluating the government agencies was different to that employed in 2013 and 2014. In 2012 a questionnaire/data-collection tool was sent to each agency to establish a baseline in terms of contract numbers, NFP numbers and identity, values of contracts, service types and so on. Once these data were collected and analysed, a semistructured interview was undertaken with the seven government agencies that commissioned the majority of contracts involving NFP human service delivery. Indeed, the seven agencies making up this group accounted for 94 per cent of the value of commissioned contracts with the NFP sector and 87 per cent of 
the number of contracts. These interviews examined topics associated with the DCSP Policy such as the extent to which the policy had been implemented, the issues raised on the government side as a result and the extent to which outcomes could be identified, and contracts developed based on them.

\section{NFP survey}

After the initial identification of relevant NFPs as a result of the first year's research involving government agencies, each year from 2012 key state government agencies were requested by Treasury to provide a current list of email addresses for the chief executive or key contact within each funded NFP organisation commissioned to provide services on behalf of the state government, and which had also received Component I of increased funding. These lists were deduplicated by the research team and, in 2012, resulted in a list of 486 individual NFP organisations together with the name and contact details of their representative. For longitudinal consistency and research efficacy, these 486 NFPs became the survey population for each of the following evaluation years. It must be acknowledged at the outset, however, that it proved difficult to maintain total consistency in the population set due, primarily, to immature data collection and contract management systems within government. The substantive population group was, however, maintained.

For the first evaluation, a questionnaire was developed and approved by the Partnership Forum working group subgroup. In relation to that first evaluation, the Partnership Forum subgroup also approved a covering email to be sent to respondents describing the purpose of the survey and containing a link to the questionnaire. The questionnaire was uploaded into Qualtrics survey software and tested with a small number of representatives of NFP organisations to check structure, terminology, flow and technical aspects. Subsequent questionnaires were simply sent to the original survey population via an email from Treasury but always after being tested.

Essentially, this process was carried out each subsequent year, although the Partnership Forum and the Partnership Forum subgroup were not engaged in the survey confirmation process or communications with the NFPs after the first year. The survey questions were retained for the 2013 and 2014 iterations, though the original survey had questions 
added focusing on growth and confidence in 2013 and these were also retained in 2014. These questions allowed for a deeper analysis to be undertaken and returned important data focused on the trajectory of likely change in the structure of the NFP sector.

In each of the evaluation years 2012 and 2013, the population of 486 NFPs which had contracts for human service delivery with the state government and which received Component I were forwarded an email incorporating a link to a Qualtrics survey, which included an ethics statement and confirmation of willingness to participate.

In October 2014, a similar covering email was distributed to the population of 437 NFPs remaining of the original 486. The fall-off in numbers resulted from organisations discontinuing the provision of services commissioned by the state government. Similarly to the previous two years, in 2014 the email contained an individualised link to the survey. This approach ensured that only one response was received per organisation and only those organisations in the sample would be included in the results. The senior most person in the targeted NFP was asked to respond.

As the NFP respondents have an important, long-term relationship with government through the agencies that purchase services from them, and because the subject of the survey was considered highly topical, it was expected that all or nearly all NFP organisations would respond. A full response is also important in supporting our ability to understand the overall demographics of the sector, and as the basis for monitoring the impact of the reforms on all NFPs over time.

In each year, however, the response rate was less than expected. The final rate achieved in 2014 for total responses was 34.55 per centdown from 48.56 per cent in 2012 and a high of 48.97 per cent in 2013. In 2014, of the 437 emails distributed, 151 NFPs responded: 138 or 91.39 per cent completed the survey in full; another 13 or 8.61 per cent submitted a partial response. The final sample included in the survey and summarised in the report was therefore variable, with a minimum sample size of 167 . The year-on-year response rates are provided in Table 4.1. 
THE THREE SECTOR SOLUTION

Table 4.1: Year-on-year response rates

\begin{tabular}{|l|r|r|r|}
\hline Evaluation & 2012 & 2013 & 2014 \\
\hline Survey date & November 2012 & September 2013 & October 2014 \\
\hline Population & 486 & 486 & 437 \\
\hline Survey respondents & 236 & 238 & 151 \\
\hline $\begin{array}{l}\text { Percentage of population } \\
\text { responded }\end{array}$ & $48.56 \%$ & $48.97 \%$ & $34.55 \%$ \\
\hline Completed responses & 181 & 167 & 138 \\
\hline Percentage completed responses & $76.69 \%$ & $70.17 \%$ & $91.39 \%$ \\
\hline Partial responses & 55 & 71 & 13 \\
\hline Percentage partial completions & $23.31 \%$ & $29.83 \%$ & $8.61 \%$ \\
\hline
\end{tabular}

Source: Author's compilation.

While the response rates were not as high as expected, they are sufficient for a reliable interpretation of the results. Completed survey responses declined from 236 in 2012 to 151 in 2014, while the population was reduced by 10.1 per cent due to the fact that 49 NFPs were no longer being commissioned. As the government did not want to make responses mandatory, the survey relied on the goodwill of the sector to respond. Likely causes of the declining response rate between 2012 and 2014 include that the sector has been the target of considerable research in recent history and 'respondent exhaustion' is likely to have ensured smaller response and completion rates. Further, it may be the case that the initial burst of enthusiasm accompanying the launch of the DCSP Policy had faded by 2014 and the sector may have had insufficient interest in the policy such that responding to the survey was lower in the priorities of senior managers.

Further, there was a rise in response rates and completion rates in 2013. This can be explained by the fact that, in 2012, relatively few contracts were established under the DCSP Policy (Gilchrist 2013: 23), while in 2013 agencies reported that 367 of the 1,373 contracts with NFPs were established under the policy and both agencies and NFPs were reporting that administration impacts were considerable, as was the complexity of contracting under the DCSP Policy, primarily due to the requirement to contract for outcomes rather than outputs (Gilchrist and Knight 2014: 41-42, 45). It is likely that the DCSP Policy was impacting on NFPs in a practical way in 2014, and the challenges 
that had incentivised NFPs to respond to the survey previously to ensure their frustrations were recorded were less of a dominating factor by the end of 2014 .

\section{Limitations on the interpretation of findings}

There were no data on the total population of contracting NFP organisations regarding turnover, employment, sector of operation or location. As such, it is not possible to determine whether the 2012, 2013 or 2014 surveys fully reflected the state government-funded sector in its entirety. The organisations that responded to the survey in each year have similar profiles in terms of turnover and location of service delivery, but differ in total employment and sector of operation. For instance, 64 organisations were identified as having responded to both the 2012 and the 2013 surveys. The differences in the survey samples were taken into consideration in the analysis. The government agencies responding to the survey are considered to be reflective of the impact of the DCSP Policy on government agencies primarily because they undertake the majority of such activity.

\section{Findings}

In considering the findings, I have presented the survey results for each sector below in consecutive subsections and then provided concluding remarks in the next section. Suffice to say, the results reported here constitute the most significant findings and a number of minor or lesser results have been left out due to space limitations. The primary results reported are those for 2014, with comparatives for previous years considered where useful to the reader in understanding the trajectory of change or the results reported. I begin with some high-level results pertaining to the government side to place the following NFP results in context.

\section{DCSP Policy implementation: A brief comment on the government side}

In 2014, 13 state government agencies were invited to participate in the evaluation (seven in 2012; 13 in 2013) and 12 responded (seven in 2012; 11 in 2013). The 2014 respondents accounted for 99 per cent of the 
$\$ 1.428$ billion in 2014-15 estimated contract value and for 98 per cent of relevant contracts. Agencies reported that there were approximately 200 full-time equivalent positions working in procurement - up from 164.5 in $2012 .{ }^{1}$ The procurement and contract management databases used by agencies varied in their capacity to provide information. The total number of service agreements was reported as 1,443 , but this was not consistent with other data provided and is unlikely to be comparable with the 2012 total reported of $994 .^{2}$ The use of preferred service provider (PSP) status (requiring less ongoing administrative activity) varied from zero to 100 per cent depending on the agency. Based on the information provided in 2014, 65 per cent of service agreements were established on a PSP basis. Further, 963 contracts were reported as being compliant with the DCSP Policy compared with 367 in 2013.

In implementing a more balanced contracting framework, the DCSP Policy also requires agencies to establish longer-term contracts to give NFPs confidence and longevity of funding and to reduce administrative burden. The survey results identified that nearly all service agreements were for periods of three years or longer. The 2014 survey identified that the intention of agencies was, by and large, to extend these contract periods to reduce the administrative burden attendant on recontracting processes. Some 43 per cent of contracts were three to five years in length, while 11 per cent were reported as extending beyond five years.

\section{Results: NFP sustainability}

In assessing sustainability, the DCSP Policy was evaluated in terms of employment numbers, investment capacity and investment, and new employment intention. Given that part of the purpose of the DCSP Policy is to maintain and enhance sustainability via the provision of a sustainable price, the evaluation of employment numbers, investment capacity and confidence, as represented by intention to invest, are all indicators of longitudinal improvement or decline in organisations' perspectives of their sustainability.

1 This excludes staff not attached to central procurement offices or working only occasionally in procurement as part of their other duties.

2 For instance, Treasury reported 1,546 relevant agreements. 
Employment numbers and employment intention are indications of sustainability and confidence. The 2014 survey identified that staff vacancies had fallen since 2013, with 69 per cent of respondents reporting that they had no unfilled positions, compared with 56 per cent in 2012, representing a vacancy rate of about 3 per cent. Given that 73 per cent of the Component I increased funding was used to supplement salaries (Gilchrist 2013), respondents reported higher staff morale and responded positively to the impact of the policy in this regard. However, it must also be remembered that the WA economy had a concurrent easing of growth as the minerals boom declined, so these employment results are not necessarily reflective of the impact of the DCSP Policy. The overall impact of the declining economic conditions probably also had an impact on the decline in the reported time taken to fill vacancies since 2012. Respondents reported that 58 per cent of vacancies were filled within four weeks, while a further quarter of vacancies were filled within the five to eight-week period. Compared with 2012 and 2013, this change signalled a positive shift in the time taken to fill vacancies.

Further, 38 per cent of respondents reported that they had more staff than in 2013, while only 9 per cent reported that they had fewer staff. This finding needs to be considered in terms of the size of the respondent organisation, where 70 per cent of organisations with a turnover of more than $\$ 10$ million reported that they had more staff, while only 23 per cent of organisations with turnover of $\$ 2$ million or less reported having more staff and 12 per cent of those small organisations reported having fewer staff.

In terms of confidence, 85 per cent of respondents reported that their organisation was in a stronger position than in 2013, continuing the consistent reporting of positive opinions relating to NFPs' capacity. However, the same dichotomy seems to have manifested in this context as in the employment section above. Smaller organisations reported less confidence in their capacity compared with larger organisations. Specifically, 73 per cent of organisations turning over \$5 million or more reported that they were stronger than at the same time in 2014 compared with only 59 per cent of organisations with a turnover of less than $\$ 2$ million. 
When considering aspects of financial sustainability and investment intent, respondents reported that they had confidence in being able to meet their debts as and when they fell due, with 97 per cent reporting that they had at least adequate capacity to pay debts. This result is an improvement on that reported in 2012, as 73 per cent of respondents reported that their organisation was very strong in being able to meet its debts compared with 67 per cent responding in the same way in 2012. This improvement is very likely associated with the payment of Component I increased funding.

This optimism in financial outcomes was replicated when prospective investment in the replacement of existing assets or the purchase of new assets was considered. Some 78 per cent of respondents reported that they believed their organisation had at least adequate capacity to replace assets in 2012 and, again in 2014, a marginal improvement was reported as 47 per cent of those reporting positively in 2014 considered that they were strong in this area compared with 42 per cent in 2012. Having said this, there appears to be a consistent group of organisations at the other end of the scale reporting that they believe they are weak in this area (22 per cent in 2012 and 2014).

In terms of investing in new assets, respondents were marginally less optimistic, with 33 per cent reporting that they were strong in the area in 2012 compared with 27 per cent in 2013. This picture is reinforced when data are disaggregated by organisational turnover. For instance, in 2014, 87 per cent of organisations with a turnover of more than $\$ 10$ million reported that they were in a strong or very strong position with respect to paying debts when they fell due compared with 62 per cent of those with a turnover of less than $\$ 500,000$ and 65 per cent of those with a turnover of between $\$ 500,000$ and $\$ 1$ million. Interestingly, the organisations reporting as most able to invest in assets to improve the quantity or quality of their services were those turning over $\$ 2$ million to $\$ 45$ million (67 per cent compared with 59 per cent in the turnover category of more than $\$ 10$ million).

In terms of organisational capacity to pursue the mission, there remained a strong dichotomy in results when large organisations were compared with smaller organisations. Overall, in 2014, 81 per cent of respondents stated that they believed their capacity to meet their mission was strong or stronger compared with 73 per cent in 2012. 
However, when size is considered, smaller NFPs were less optimistic than larger NFPs. Some 87 per cent of larger NFPs (turning over $\$ 10$ million or more) reported that they expected to be stronger or much stronger in terms of capacity to meet mission in the future compared with 76 per cent of those organisations turning over $\$ 1$ million to $\$ 2$ million, or 78 per cent of those turning over between $\$ 500,000$ and $\$ 1$ million. Overall, 87 per cent of organisations turning over $\$ 10$ million or more reported that they expected to be stronger-10 per cent more than the average of all of the smaller organisations.

\section{The impact of the DCSP Policy on NFPs}

While evaluating perceptions of sustainability is critical, this section reports on questions raised in the survey pertaining to the DCSP Policy itself and the impact it has had on NFPs contracting with government. In making this assessment, each annual survey asked questions pertaining to capacity for implementation, outcomes development and management, data collection and reporting, and perceptions of administrative burden.

An important aspect of the implementation of the DCSP Policy is the level of knowledge apparently held by NFPs in relation to the policy. Between 2012 and 2013, NFPs reported a significant increase in their rating of knowledge pertaining to the DCSP Policy. Indeed, in 2012, 46 per cent of respondents reported that they had a 'good' or 'very good' level of knowledge pertaining to the policy and, by 2013, this had risen to 76 per cent. However, the 2014 results indicate that the respondents are less confident in their knowledge of the policy. Indeed, only 55 per cent of respondents reported that they believed they had 'good' or 'very good' knowledge. It is likely this latest response gives a more realistic view of understanding, as these organisations would, over this time, have developed a greater appreciation of the complexity that the DCSP Policy represents in terms of administration, outcomes identification and reporting - an appreciation that would likely come of lived experience.

Axiomatically, the implementation of a policy such as the DCSP will result in administrative increases as individualised funding and personcentred care lead to a dramatic increase in numbers of contracts to be administered, and outcomes identification and reporting result in greater 
complexity of recording and reporting data. While in 2013 respondents reported that they felt the time taken to establish and manage a new contract had increased since 2012 (30 per cent reported an increase in elapsed time to final arrangements in 2012, compared with 40 per cent in 2013 and 26 per cent in 2014; 24 per cent reported an increase in time taken to manage contracts in 2012, compared with 50 per cent in 2013 and 37 per cent in 2014), overall, there were improvements in reported administrative time taken between 2013 and 2014.

NFP respondents' comments on the implementation of the DCSP Policy were mostly mixed (Knight and Gilchrist 2015: 41). There was frustration with inconsistent approaches being used across agencies and a perception of increased administrative burden. This is an interesting finding given that the focus of the policy is on individual recipient satisfaction with expected concomitant reductions in administrative burden. However, it is to be expected that increased administrative burden will flow out of the process of policy adoption as, for instance, block-funding contracts will be replaced with individual contracts focused on individual recipients.

\section{Concluding remarks}

The above review of the DCSP Policy evaluation undertaken in 2012, 2013 and 2014 is necessarily limited in its capacity to communicate the full findings of the study undertaken due to space constraints. The major findings relate to the impact of administrative burden, and much of that arose out of the change from the contractual focus on outputs to outcomes and from block-funding arrangements to individualised funding and person-centred services. Reported increases in time taken to agree on contractual arrangements and to devise suitable outcomes indicators capable of being metricised and reported were substantial. These increases in difficulty and administrative burden are likely to have arisen out of the complexity associated particularly with the identification of outcomes in the context of the human services subsector. This is the sector where most of the WA Government funding is allocated.

It is still too early to assess the aspects of the DCSP Policy associated with individualised funding and person-centred care from the recipient's perspective. These two aspects of the policy relate to the 
person-focused improvements anticipated in the policy, which were identified by the original audit committee. Other research undertaken by me has identified that it is highly likely that additional difficulties will arise with respect to administrative burden and increased clinical risk. This burden is somewhat denied by a commentariat and policy community that desire a reduction in red tape while increasing the administrative burden associated with individualised contracting arrangements. Indeed, some administrative burden is absolutely necessary but it does cost money. A lack of funding made available to support the change management process represents a challenge for both agencies and the NFP sector, and this lack will likely have an impact on the ongoing move towards person-centred care and individualised funding in future years (see, for instance, Gilchrist and Knight 2014).

Finally, there is also a need for ongoing and increased partnership between government and the NFP sector to achieve the outcomes sought in the DCSP Policy itself. Funding for training and change management resources will be required over the next few years. Analysis of the survey results associated with each category of organisation indicated that there is still a sense of the respective camps standing off from each other. The key question that only experience will answer is whether or not the DCSP Policy will result in real partnership between government and the NFP sector.

Future research will focus on the impact on government and the extent to which outcomes management is likely to be achieved within the context of the DCSP Policy. Further, as the DCSP Policy impacts on the structure of the NFP sector, further research is being undertaken in the areas of change management and supported structural reform. Additionally, it is expected that some variation will occur in the application of the policy, as some human services are particularly suited to outcomes reporting within a framework of individualised funding and person-centred care. However, other services are not and it is expected that block and other forms of funding will be continued in relation to these areas. 


\section{References}

Barraket, J., ed. 2008. Strategic Issues for the Not-for-Profit Sector. Sydney: UNSW Press.

Center for Law and Social Policy. 2014. Social Impact Bonds: Overview and considerations. Washington, DC: Center for Law and Social Policy. Available from: clasp.org/resources-and-publications/ publication-1/CLASP-Social-Impact-Bonds-SIBs-March-2014.pdf (accessed 22 April 2016).

Economic Audit Committee. 2009. Putting the public first: Partnering with the community and business to deliver outcomes. Report to the WA Government, Perth.

Frumkin, P. 2002. On Being Nonprofit: A conceptual and policy primer. London: Harvard University Press.

Garton, J. 2009. The Regulation of Organised Civil Society. Oxford: Hart Publishing.

Gilchrist, D. J. 2013. 2012 Evaluation of the Sustainable Funding and Contracting with the Not-for-Profit Sector Initiatives and Associated Procurement Reforms. Perth: WA Government.

Gilchrist, D. J. and P. A. Knight. 2013a. Annual funded sector report. Report prepared for the Disability Services Commission, Perth.

Gilchrist, D. J. and P. A. Knight. 2013b. 2013 Evaluation of the Sustainable Funding and Contracting with the Not-for-Profit Sector Initiatives and Associated Procurement Reforms. Perth: WA Government.

Gilchrist, D. J. and P. A. Knight. 2014. Community employers, person centred care and individualised funding: Final report. Joint report undertaken with Community Employers WA, Perth.

Knight, P. A. and D. J. Gilchrist. 2015. 2014 Evaluation of the Sustainable Funding and Contracting with the Not-for-Profit Sector Initiatives and Associated Procurement Reforms. Perth: WA Government. 
McGregor-Lowndes, M. 2008. 'Is there something better than partnership?' In Strategic Issues for the Not-for-Profit Sector, ed. J. Barraket, 45-73. Sydney: UNSW Press.

Mendes, P. 2008. Australia's Welfare Wars Revisited: The players, the politics and the ideologies. Sydney: UNSW Press.

National Audit Office (NAO). 2005. Working with the Third Sector. London: National Audit Office. Available from: nao.org.uk/wpcontent/uploads/2005/06/050675.pdf (accessed 14 August 2013).

Office of the Auditor-General, Western Australia (OAG WA). 1998. Accommodation and Support Services to Young People Unable to Live at Home. Perth: Office of the Auditor-General. Available from: audit.wa.gov.au/wp-content/uploads/2013/05/report98_11.pdf (accessed 8 August 2013).

Office of the Auditor-General, Western Australia (OAG WA). 2000. A Means to an End: Contracting Not-for-Profit Organisations for the Delivery of Community services. Perth: Office of the Auditor-General. Available from: audit.wa.gov.au/wp-content/uploads/2013/05/ report2000_03.pdf (accessed 8 August 2013).

Office of the Auditor-General, Western Australia (OAG WA). 2003. Contracting Not-for-Profit Organisations for Delivery of Health Services. Perth: Office of the Auditor-General. Available from: audit.wa.gov.au/wp-content/uploads/2013/05/report2003_02.pdf (accessed 12 August 2013).

Office of the Auditor-General, Western Australia (OAG WA). 2012. Working Together: Management of partnerships with volunteers. Perth: Office of the Auditor-General. Available from: audit.wa.gov.au/wp-content/uploads/2013/05/report2012_01.pdf (accessed 12 August 2013).

Office of the Auditor-General, Western Australia (OAG WA). 2013a. Delivering Western Australia's Ambulance Services. Perth: Office of the Auditor-General. Available from: audit.wa.gov.au/wp-content/ uploads/2013/06/report2013_05.pdf (accessed 12 August 2013). 
Office of the Auditor-General, Western Australia (OAG WA). 2013b. Sustainable Funding and Contracting with the Not-For-Profit Sector - Component I. Perth: Office of the Auditor-General. Available from: audit.wa.gov.au/wp-content/uploads/2013/09/report2013_13Component-1-Funding.pdf (accessed 19 September 2013).

Productivity Commission. 2010. Contribution of the Australian not-forprofit sector. Research Report. Productivity Commission, Canberra.

Public Accounts Committee, Western Australia (PAC WA). 2000. Accountability and not-for-profit organisations. Report No. 49. Public Accounts Committee, Perth. Available from: parliament. wa.gov.au/parliament/homepage.nsf (accessed 14 August 2013).

Roth, L. 2011. Social impact bonds. e-Brief. New South Wales Parliamentary Library Research Service, Sydney. Available from: www.parliament.nsw.gov.au/researchpapers/Documents/socialimpact-bonds/e-briefsocial\%20impact\%20bonds.pdf (accessed 19 May 2016).

Salamon, L. M. 1995. Partners in Public Service: Government-nonprofit relations in the modern welfare state. Baltimore: The Johns Hopkins University Press.

Victorian Auditor-General's Office (VAGO). 2013. Implementation of the Strengthening Community Organisations Action Plan. Melbourne: Victorian Auditor-General's Office. Available from: audit.vic.gov. au/publications/20131016-Community-Action-Plan/20131016Community-Action-Plan.pdf (accessed 19 October 2013).

WA Government. 2011. Delivering Community Services in Partnership: A policy to achieve better outcomes for Western Australians through the funding and contracting of community services. Perth: WA Government.

Young, D. R. 2006. 'Complimentary, supplementary or adversarial: Nonprofit-government relations.' In Nonprofits \& Government: Collaboration and conflict, eds E. T. Boris and C. E. Streuerle, 37-80. 2nd edn. Washington, DC: The Urban Institute Press. 
This text is taken from The Three Sector Solution: Delivering public policy in collaboration with not-for-profits and business, edited by John Butcher and David Gilchrist, published 2016 by ANU Press, The Australian National University, Canberra, Australia. 